\title{
ק-Cyclodextrin/Diol Phase Silica Materials for Direct Injection Analysis of Drug Enantiomers in Serum by Liquid Chromatography
}

\author{
Jun Haginaka ${ }^{\dagger}$ and Junko WaKaI \\ Faculty of Pharmaceutical Sciences, Mukogawa Women's University, \\ Koshien Kyuban-cho, Nishinomiya 663, Japan
}

\begin{abstract}
$\beta$-Cyclodextrin (CD)/diol phase silica materials have been designed for direct serum injection assays of drug enantiomers. The mixed functional phase (MFP) materials having $\beta$-CD and diol phases were synthesized in four steps: introduction of a 3-chloropropyl phase, introduction of a $\beta-C D$ phase by ether linkage, introduction of a 3glycidoxypropyl phase and hydrolysis of the oxirange ring to a diol phase. The obtained MFP materials were more stable against continuous flow of an eluent including phosphate buffer and organic solvent and/or acid hydrolysis than only $\beta$-CD-bonded materials were. These MFP materials could be used for direct serum injection assays of drug enantiomers. The recovery of drug enantiomers from serum was almost $100 \%$.
\end{abstract}

Keywords $\beta$-Cyclodextrin-bonded silica, $\beta$-cyclodextrin/diol phase silica, direct serum injection, mixed functional phase, hexobarbital enantiomer, mephobarbital enantiomer, ibuprofen enantiomer

Recently, specially designed packing materials have been developed for direct serum injection assays of drugs. ${ }^{1-3}$ These materials can exclude serum proteins without denaturing, and still retain a drug and its metabolite(s). In previous papers, we reported preparation methods of mixed functional phase (MFP) silica materials having phenyl/diol ${ }^{4,5}$ or alkyl/diol phases ${ }^{5}$ for achiral drugs and $\beta$-cyclodextrin $\left(\beta\right.$-CD)/ diol phases ${ }^{6}$ for chiral drugs. Also, these materials could be used for direct serum injection assays of drugs without increase of back pressure or decrease of column efficiency.

The $\beta$-CD/diol materials reported previously ${ }^{6}$ were prepared in three steps: introduction of a 3-glycidoxypropyl phase; introduction of a $\beta-C D$ phase; and hydrolysis of the oxirane ring to a diol phase, where $\beta$ $\mathrm{CD}$ is bonded to the base silica materials by carbamate linkage, as reported by Fujimura et al. ${ }^{7}$ Armstrong and Ward reported that the nitrogen-containing linkage was hydrolytically unstable ${ }^{8}$, and reported a preparation method of a $\beta$-CD-bonded material by ether linkage. ${ }^{9}$ Thus, we tried to prepare $\beta-\mathrm{CD} /$ diol phase materials for direct serum injection assays of drug enantiomers, where $\beta-C D$ is bonded to a silica gel by ether linkage, as reported by Armstrong.9

First, the $\beta-C D /$ diol phase materials were prepared in four steps: introduction of a 3-glycidoxypropyl phase, introduction of a 3-chloropropyl phase, introduction of a $\beta-C D$ phase by ether linkage and hydrolysis of the oxirane ring to a diol phase. The obtained materials were very unstable for continuous flow of an eluent including phosphate buffer and organic solvent. This paper deals with stabilization of the $\beta-C D /$ diol phase materials, and with application of the $\beta-\mathrm{CD} /$ diol phase materials to direct serum injection assays of drug enantiomers.

\section{Experimental}

\section{Reagents and materials}

3-Glycidoxypropyl trimethoxysilane, $\beta-\mathrm{CD}$ and bovine serum albumin (BSA) were purchased from Nacalai Tesque (Kyoto, Japan). Acetonitrile of an HPLC grade was also purchased from Nacalai Tesque. 3-Chloropropylmethyldimethoxysilane was obtained from Petrach Systems (Bristol, PA, USA). Crystalline sodium hydride and mephobarbital were purchased from Aldrich (Milwaukee, WI, USA) and Sigma (St. Louis, MO, USA), respectively. The other reagents of analytical grade and control human serum (Control Serum I) were purchased from Wako Pure Chemicals (Osaka, Japan). Hexobarbital and ibuprofen were kindly donated by Teikoku Chemical Industry (Osaka) and Kaken Seiyaku (Tokyo, Japan), respectively. Chemcosorb silica gels (particle diameter, $5 \mu \mathrm{m}$; nominal pore size, $80 \AA$; specific surface area, $450 \mathrm{~m}^{2} / \mathrm{g}$ ) was obtained from Chemco Scientific (Osaka).

Water purified by a Nanopure II unit (Barnstead, Boston, MA, USA) was used for the preparation of the eluent and the sample solution.

\footnotetext{
$\dagger$ To whom all correspondence should be addressed.
} 

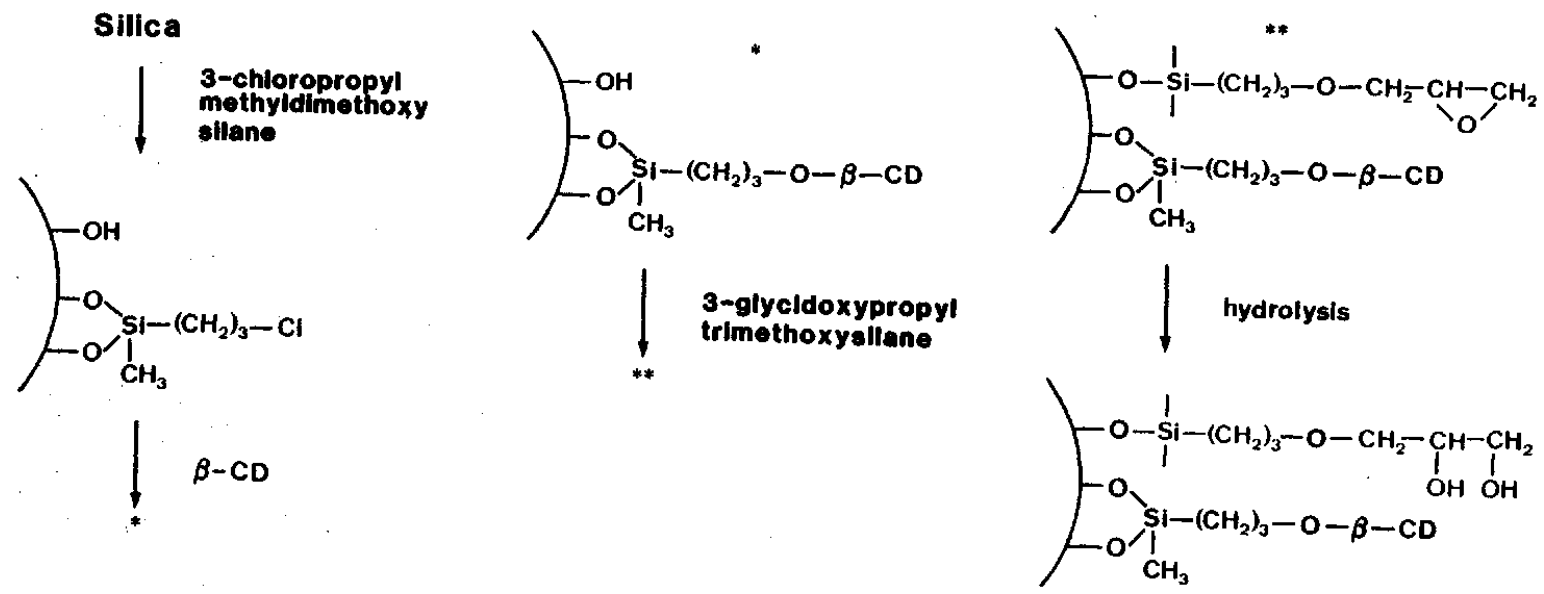

Fig. 1 Synthetic route for $\beta-\mathrm{CD} /$ diol phase materials.

\section{Preparation of $\beta-C D /$ diol phase materials}

As shown in Fig. 1, the MFP materials having $\beta$-CD and diol phases were prepared in four steps: introduction of a 3-chloropropyl phase, introduction of a $\beta$-CD phase by ether linkage, introduction of a 3-glycidoxypropyl phase and hydrolysis of the oxirane ring to a diol phase. Introduction of a 3-chloropropyl phase. Four grams of Chemcosorb silica gels were dried in vacuo over $\mathrm{P}_{2} \mathrm{O}_{5}$ at $150^{\circ} \mathrm{C}$ for $6 \mathrm{~h}$. The dry silica gel was added to $75 \mathrm{ml}$ of dry toluene. The mixture was heated to reflux until all the water had been removed as an azeotrope into a DeanStark type trap. To the mixture, $3.6 \mathrm{ml}$ of 3-chloropropylmethyldimethoxysilane, which was equivalent to $12 \mu \mathrm{mol}$ per square meter of surface area, was added. After being refluxed for $6 \mathrm{~h}$, the reaction mixture was cooled to room temperature, filtered, and washed with toluene and methanol. The isolated silica gel was then dried in vacuo over $\mathrm{P}_{2} \mathrm{O}_{5}$ at $60^{\circ} \mathrm{C}$ for $2 \mathrm{~h}$.

Introduction of $a-C D$ phase. Introduction of $\beta-C D$ was performed according to the method reported by Armstrong.9 Four grams of $\beta-C D$, dried in vacuo over $\mathrm{P}_{2} \mathrm{O}_{5}$ at $100^{\circ} \mathrm{C}$ for $4 \mathrm{~h}$, was dissolved in $80 \mathrm{ml}$ of dry $N, N$ dimethylformamide (DMF). To the solution, $1.2 \mathrm{~g}$ of crystalline sodium hydride $(\mathrm{NaH})$ was added. The mixture was allowed to react for $15 \mathrm{~min}$ while it was stirred. The above steps were performed under a dry $\mathrm{N}_{2}$ atmosphere. The reaction mixture was then filtered to remove the excess $\mathrm{NaH}$. The filtrate was immediately added to the 3-chloropropyl silica gel, four grams of which had been slurried earlier in $50 \mathrm{ml}$ of DMF. Then the mixture was refluxed for $2.5 \mathrm{~h}$. The reaction mixture was cooled to room temperature, filtered, and washed with DMF, methanol, toluene, methanol, water and methanol. The isolated silica gel was dried in vacuo over $\mathrm{P}_{2} \mathrm{O}_{5}$ at $60^{\circ} \mathrm{C}$ for $2 \mathrm{~h}$.

Introduction of a 3-glycidoxypropyl phase. To $4 \mathrm{~g}$ of the $\beta$-CD-bonded silica, $140 \mathrm{ml}$ of toluene was added. To the mixture, $3.4 \mathrm{ml}$ of 3-glycidoxypropyltrimethoxysilane, which was equivalent to $8 \mu \mathrm{mol}$ per square meter of surface area, was added, and the mixture was then reacted at $95^{\circ} \mathrm{C}$ for $6 \mathrm{~h}$.
The reaction mixture was cooled to room temperature, filtered, and washed with toluene and methanol. The isolated silica gel was dried in vacuo over $\mathrm{P}_{2} \mathrm{O}_{5}$ at $60^{\circ} \mathrm{C}$ for $2 \mathrm{~h}$.

Hydrolysis of the oxirane ring to a diol phase. To $4 \mathrm{~g}$ of the $\beta$-CD/3-glycidoxypropyl phase silica, $150 \mathrm{ml}$ of perchloric acid ( $\mathrm{pH} 3.5$ ) including 5\% acetonitrile was added, and then the mixture was reacted at $90^{\circ} \mathrm{C}$ for $2 \mathrm{~h}$. The reaction mixture was cooled to room temperature, filtered, and washed with distilled water and methanol. The isolated silica gel was dried in vacuo over $\mathrm{P}_{2} \mathrm{O}_{5}$ at $60^{\circ} \mathrm{C}$ for $2 \mathrm{~h}$. The $\beta-\mathrm{CD} /$ diol phase materials obtained were abbreviated to $\beta-\mathrm{CD}-8 \mathrm{G}$ silica, taking into account the number of micromoles of 3-glycidoxypropyltrimethoxysilane per square meter of surface area used for the reaction.

\section{Instrumentation}

The reacted amounts of 3-chloropropylmethyldimethoxysilane, $\beta$-CD and 3-glycidoxypropyltrimethoxysilane were determined by elemental analysis $(C, H, N)$ using a Model NC-80AUTO analyzer (Sumika Chemical Analysis Service, Osaka, Japan).

The prepared $\beta-\mathrm{CD} /$ diol phase material was packed into a $150 \times 4.6 \mathrm{~mm}$ i.d. stainless steel tube by conventional high-pressure slurry-packing procedure.

The chromatographic system was composed of a Model 880 pump (Japan Spectroscopic, Tokyo, Japan) equipped with a variable wavelength detector (a Model 875-UV, Japan Spectroscopic). The eluents used were as follows: $50 \mathrm{mM} \mathrm{NaH} \mathrm{PO}_{4} / 50 \mathrm{mM} \mathrm{Na}_{2} \mathrm{HPO}_{4}$ /acetonitrile $=2.5 / 2.5 / 1(\mathrm{v} / \mathrm{v})$ for the separation of hexobarbital and mephobarbital enantiomers; and $30 \mathrm{mM}$ $\mathrm{NaH}_{2} \mathrm{PO}_{4} / 70 \mathrm{mM} \mathrm{Na} \mathrm{HPO}_{4} /$ acetonitrile $=3 / 3 / 1(\mathrm{v} / \mathrm{v})$ for ibuprofen enantiomers. The flow rate was maintained at $0.6 \mathrm{ml} / \mathrm{min}$, respectively. Detection was performed at 240 or $230 \mathrm{~nm}$. A precolumn $(50 \times 4.6 \mathrm{~mm}$ i.d.) packed with LC-sorb Sp-A-ODS (particle size, 25 $40 \mu \mathrm{m}$, Chemco Scientific) was inserted between the pump and injector to protect the analytical column from microparticles in the eluent and to saturate the eluent 
with silica. Samples were injected with a SIL-9A Auto Injector (Shimadzu, Kyoto, Japan). The chromatograms were recorded and integrated using a Chromatopac C-R6A (Shimadzu). All separations were carried out at ambient temperature.

\section{Preparation of a human serum sample}

Hexobarbital, mephobarbital or ibuprofen was dissolved in human serum at a known concentration, and an appropriate volume of serum sample was applied to the $\beta$-CD-8G silica material after filtration through a $0.22-\mu \mathrm{m}$ membrane filter (Nippon Millipore, Tokyo).

\section{Results and Discussion}

\section{Preparation of $\beta-C D /$ diol phase materials}

Preliminarily, we prepared only $\beta$-CD-bonded materials in two steps: introduction of a 3-chloropropyl phase and introduction of a $\beta$-CD phase by ether linkage. When $50 \mathrm{mM}$ phosphate buffer $(\mathrm{pH} 6.9) /$ acetonitrile $=4 / 1(\mathrm{v} / \mathrm{v})$ was passed through onto the $\beta$-CD-bonded materials at a flow rate of $0.8 \mathrm{ml} / \mathrm{min}$ at ambient temperature for $180 \mathrm{~h}$, the capacity factor of the first eluted hexobarbital enantiomer was decreased from 6.1 to 2.2, and the enantioseparation factor dropped from 1.13 to 1.12 . These results reveal that only $\beta$-CD-bonded materials are unstable against continuous flow of an eluent including phosphate buffer and organic solvent. The prepared $\beta$-CD-bonded materials were then subjected to acid hydrolysis $(\mathrm{pH} 3.5)$ at $90^{\circ} \mathrm{C}$ for $2 \mathrm{~h}$. As shown in Table 1 (see, $\beta$-CD materials before purge), the capacity factor and enantioseparation factor of first eluted hexobarbital enantiomer were found to be 1.28 and 1.10, respectively, by using $50 \mathrm{mM}$ phosphate buffer $(\mathrm{pH}$ 6.9)/acetonitrile $=8 / 1(\mathrm{v} / \mathrm{v})$ as an eluent. Thus, it is found that $\beta$-CD species are lost from the columns by continuous flow of hydro-organic solvent and/or by acid hydrolysis.

Next, we prepared $\beta-C D /$ diol phase materials by further introduction of a 3-glycidoxypropyl phase and acid hydrolysis of the oxirane ring to a diol phase. As shown in Table 1, the $\beta$-CD/diol phase materials gave higher enantioselectivity for hexobarbital and mephobarbital than the only $\beta$-CD-bonded materials, and were more stable against acid hydrolysis and continuous purge of an eluent including phosphate buffer and organic solvent. On the other hand, those $\beta$-CD/diol phase materials prepared by introduction of a 3-glycidoxypropyl phase, introduction of a 3-chloropropyl phase, introduction of $\beta-C D$ phase, and hydrolysis of the oxirane ring to a diol phase, were unstable against the acid hydrolysis and continuous purge of the eluent. These results suggest that the $\beta$-CD-bonded materials are stabilized by further introduction of diol phases. Further introduction of diol phases might prevent loss of $\beta$-CD phases from the column by formation of polymeric diol phases. In a previous report ${ }^{6}$, we prepared $\beta-C D /$ diol phase materials by three steps: introduction of a 3glycidoxypropyl phase, introduction of a $\beta$-CD phase and hydrolysis of the oxirane ring to a diol phase, where $\beta-C D$ is bonded by carbamate linkage. As described above, we prepared the $\beta$-CD/diol phase materials by introduction of a $\beta$-CD phase, followed by introduction of a 3-glycidoxypropyl phase and hydrolysis of the oxirane ring to a diol phase. The packing materials having the same retention properties and column efficiency were obtained by the two methods. This supports the conclusion that the prepared materials have mixed functional phase composition of $\beta-\mathrm{CD}$ and diol groups.

By altering the amount of 3-glycidoxypropyltrimethoxysilane used for the reaction, we obtained the optimum $\beta$-CD/diol material, $\beta$-CD-8G silica, for direct serum injection assays of drug enantiomers. Elemental analysis data reveal that surface coverage of the $\beta$-CD and diol phases are 0.20 and $2.0 \mu \mathrm{mol} / \mathrm{m}^{2}$. Also, after acidic hydrolysis of the oxirane ring to a diol phase, about $10 \%$ of $\beta$-CD-bonded phases was lost from the column. Previously ${ }^{6}$, we reported that only $\beta$-CDbonded materials showed low protein recovery compared with the $\beta-\mathrm{CD} /$ diol phase materials. This is true in this case: $70 \%$ for only $\beta$-CD bonded materials and $100 \%$ for the $\beta$-CD- $8 \mathrm{G}$ silica materials.

\section{Direct injection analysis of drug enantiomers in serum}

Another aim of this study is application of the $\beta-C D /$ diol phase materials to direct serum injection assays of drug enantiomers. Figures 2 and 3 show chromatograms from direct injection assays of hexobarbital and

Table 1 Comparison of stability of $\beta-C D$ and $\beta-C D /$ diol phase materials ${ }^{\mathrm{a}}$

\begin{tabular}{|c|c|c|c|c|c|c|c|c|}
\hline & \multicolumn{4}{|c|}{ Before purge } & \multicolumn{4}{|c|}{ After purgeb } \\
\hline & \multicolumn{2}{|c|}{ Hexobarbital } & \multicolumn{2}{|c|}{ Mephobarbital } & \multicolumn{2}{|c|}{ Hexobarbital } & \multicolumn{2}{|c|}{ Mephobarbital } \\
\hline & $k_{1}^{\prime}$ & $\alpha$ & $k_{1}^{\prime}$ & $\alpha$ & $k_{1}^{\prime}$ & $\alpha$ & $k_{1}^{\prime}$ & $\alpha$ \\
\hline$\beta-\mathrm{CD}^{\mathrm{c}}$ & 1.28 & 1.10 & 1.15 & 1.00 & 1.13 & 1.10 & 0.99 & 1.00 \\
\hline$\beta-\mathrm{CD} / \mathrm{diol}$ & 4.20 & 1.13 & 3.59 & 1.09 & 4.14 & 1.14 & 3.57 & 1.10 \\
\hline
\end{tabular}

a. Capacity factors of hexobarbital and mephobarbital were measured using $50 \mathrm{mM}$ phosphate buffer (pH 6.9)/ acetonitrile $=8 / 1(\mathrm{v} / \mathrm{v})$ at a flow rate of $0.8 \mathrm{ml} / \mathrm{min}$. b. $50 \mathrm{mM}$ phosphate buffer $(\mathrm{pH} \mathrm{6.9)} /$ acetonitrile $=8 / 1(\mathrm{v} / \mathrm{v}) \mathrm{was}$ purged at a flow rate of $0.8 \mathrm{ml} / \mathrm{min}$ and at ambient temperature for $10 \mathrm{~d}$. c. After acid hydrolysis $(\mathrm{pH} 3.5)$ at $90^{\circ} \mathrm{C}$ for $2 \mathrm{~h}$. 
A

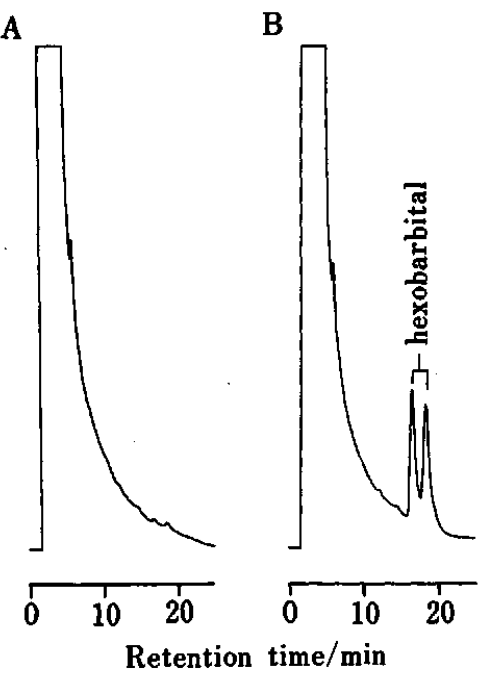

Fig. 2 Chromatogram of control serum (A) and control serum spiked with hexobarbital (B) by direct injection on the $\beta-C D /$ diol silica materials. Chromatographic conditions: eluent, $50 \mathrm{mM}$ phosphate buffer $\left(\mathrm{pH} \mathrm{6.9)} / \mathrm{CH}_{3} \mathrm{CN}=5 / 1\right.$ (v/v); flow rate, $0.6 \mathrm{ml} / \mathrm{min}$; detection, $240 \mathrm{~nm}$; concentration, $50 \mu \mathrm{g} / \mathrm{ml}$; injection volume, $20 \mu \mathrm{l}$.
A



Fig. 3 Chromatograms of control serum (A) and control serum spiked with mephobarbital (B) by direct injection on the $\beta-C D /$ diol silica materials. Chromatographic conditions as in Fig. 2.

mephobarbital, respectively, in human serum. The serum proteins were eluted in the void volume, followed by the elution of the drug enantiomers. In contrast to the previous study where mephobarbital enantiomers could not be resolved on the $\beta-\mathrm{CD} /$ diol materials ${ }^{6}$, they could be separated on the $\beta-\mathrm{CD} /$ diol materials prepared in this study. This means that the bonding method is an important factor for chiral resolution of a racemic solute. Table 2 illustrates the relative standard deviation (RSD) of the assays of the hexobarbital, mephobarbital and ibuprofen in serum samples and their recovery from the serum samples. As shown in Table 2, each enantiomer of the three racemic drugs was almost completely (98.8 -
Table 2 Reproducibility and recovery of individual enantiomers of hexobarbital, mephobarbital and ibuprofen from human serum ${ }^{\mathrm{a}}$

\begin{tabular}{ccc}
\hline Drug & RSD $^{\mathrm{b}}, \%$ & Recovery, \% \\
\hline Hexobarbital & & \\
peak 1 & & 101 \\
peak 2 & 1.89 & 98.8 \\
Mephobarbital & 1.91 & \\
peak 1 & & 102 \\
peak 2 & 2.39 & 99.1 \\
Ibuprofen & 2.72 & \\
peak 1 & & 99.2 \\
peak 2 & 2.48 & 103 \\
\hline
\end{tabular}

a. The concentrations were 50,25 and $50 \mu \mathrm{g} / \mathrm{ml}$ for hexobarbital, mephobarbital and ibuprofen, respectively.

b. Relative standard deviation (RSD) of ten analyses.

c. Peaks 1 and 2 correspond to enantiomers eluted first and second.

$103 \%$ ) recovered from serum with good reproducibility.

\section{Durability of the $\beta-C D /$ diol phase materials}

The durability of the $\beta-C D /$ diol phase materials was examined for direct injection analysis of serum samples containing hexobarbital under the conditions in Fig. 2. The retentivity and column efficiency for hexobarbital could be maintained with no change of back pressure after repetitive $20-\mu 1$ injections of as many as 300 serum samples (total injection volume, about 6-ml serum sample). The upper limit of repetitive injections has not been determined yet.

In conclusion, the $\beta-\mathrm{CD} /$ diol phase materials prepared by ether linkage were stabilized by further introduction of a diol phase, and could be used for direct serum injection analysis of drug enantiomers.

This work was supported in part by Grant-in-Aids from the Research Foundation for Pharmaceutical Sciences.

\section{References}

1. J. Haginaka, Tr. Anal. Chem., 10, 17 (1991).

2. T. C. Pinkerton, J. Chromatogr., 544, 13 (1991).

3. K. K. Unger, Chromatographia, 31, 507 (1991).

4. J. Haginaka and J. Wakai, Chromatographia, 29, 23 (1990).

5. J. Haginaka, J. Wakai and H. Yasuda, J. Chromatogr., 535, 163 (1990).

6. J. Haginaka and J. Wakai, Anal. Chem., 62, 997 (1990).

7. K. Fujimura, M. Kitagawa, H. Takayanagi and T. Ando, J. Liq. Chromatogr., 9, 607 (1986).

8. T. J. Ward and D. W. Armstrong, "Chromatographic Chiral Separations", ed. M. Zief and L. J. Crane, Chap. 5, Marcel Dekker, New York, 1988.

9. D. W. Armstrong, U. S. Patent 4,539,399, 1985.

(Received September 5, 1991)

(Accepted January 14, 1992) 